European Journal of STEM Education, 2:1 (2017), 2

ISSN: $2468-4368$

\title{
Faculty Perceptions of Student Recruitment and Retention in STEM Fields
}

\author{
Eshani Gandhi-Lee ${ }^{1}$, Heather Skaza ${ }^{2}$, Erica Marti ${ }^{1}$, PG Schrader ${ }^{1}$, MaryKay Orgill1* \\ 1 University of Nevada, Las Vegas, USA \\ ${ }^{2}$ Florida Gulf Coast University, USA \\ *Corresponding Author: marykay.orgill@unlv.edu
}

Citation: Gandhi-Lee, E., Skaza, H., Marti, E., Schrader, P. and Orgill, M. (2017) Faculty Perceptions of Student Recruitment and Retention in STEM Fields, European Journal of STEM Education, 2:1 (2017), 2. doi: http://dx.doi.org/10.20897/esteme.201702

Published: April 30, 2017

\begin{abstract}
According to the President's Council of Advisors on Science and Technology (PCAST, 2012), there is a need to produce one million more STEM (Science, Technology, Engineering, and Mathematics) graduates in the U.S. over the next decade. Thus, more students must be recruited into and retained in STEM degrees of study. Because faculty are considered influential in students' choices to pursue and remain in STEM disciplines, we interviewed university STEM faculty in order to identify their perceptions of student recruitment and retention in STEM fields. Our data indicate that faculty are generally unaware of or not worried about the need to produce additional STEM graduates. Additionally, faculty seem to be unaware of the actions they might take to positively influence STEM recruitment and retention at the post-secondary level. Here, we specifically discuss faculty perceptions of (1) the gap between the number of STEM graduates and the number of STEM workers available for STEM-related jobs, (2) why students may not be going into or remaining in STEM fields, and (3) their own roles in recruiting and retaining students in STEM fields.
\end{abstract}

Keywords: STEM pipeline, recruitment \& retention, perceptions, faculty

\section{INTRODUCTION}

An increasing number of jobs in the 21st century economic climate demand the experience and skills that a STEM education affords (National Science Board, 2015). From 2008 to 2018, STEM occupations are projected to increase by $17 \%$ compared to $9.8 \%$ for non-STEM occupations (U.S. Department of Commerce, 2011). U.S. systems of education are falling behind in producing the workforce necessary to sustain this economic progress in STEM-related areas. In 2010, for example, unemployed people outnumbered job vacancies 3.6 to one for nonSTEM occupations; however, for STEM occupations, job vacancies outnumbered unemployed people by almost two to one (Change the Equation, 2010). In his 2012 State of the Union address, President Obama highlighted this gap between the number of STEM-capable workers and the needs of businesses and the negative impact of this gap on economic growth. Subsequently, the President's Council of Advisors on Science and Technology (PCAST) Report (2012) prioritized the conferment of one million additional STEM degrees from colleges across the United States over the next decade in order to strengthen the STEM-capable workforce.

Unfortunately, the number of students that intend to join the STEM workforce decreases as they move from primary to secondary grades and into postsecondary education systems. Of the estimated 4 million students who enter 9th grade in the United States, approximately 7\% choose STEM majors at the post-secondary level. However, only $4 \%$ of those students who initially choose STEM majors ultimately graduate with a degree in those fields (National Center for Education Statistics [NCES], 2008). Moreover, a study carried out by the U.S. Department 
of Education indicates that that over half of the students who declare a STEM major during their freshman year switch out into a non-STEM major before graduating (Chen, 2009). The movement of students through the educational system is sometimes referred to as a "pipeline" of future workers. Accordingly, it is often said that the "flow" of potential workers through the STEM pipeline decreases rather significantly as students progress to higher levels of education (NCES, 2008).

Significant career decisions are made during the first two years of college (Astin \& Astin, 1992; Seymour \& Hewitt, 1977). As a result, post-secondary institutions and, in particular, faculty are in a unique position to positively influence the recruitment and retention of STEM majors (PCAST, 2012). As experts of their fields, university faculty have successfully negotiated the STEM pipeline and can offer important insights into issues pertaining to student recruitment and retention. Research suggests that that early student experiences in college are increasingly shaped by the quality of their interactions with faculty (Cejda \& Rhodes, 2010). For example, faculty in introductory STEM courses are especially instrumental in guiding and fostering student interest and expectations about STEM disciplines (Cejda \& Rhodes, 2010). Unfortunately, faculty do not always recognize the significance of their roles in the STEM pipeline (Gandhi-Lee et al., 2015). Further, very little research has examined university STEM faculty perceptions of STEM students, the STEM pipeline, and their potential impact on the recruitment and retention of students into STEM majors (Breiner et al., 2010; Brown et al., 2010; Gandhi-Lee et al., 2015). The current study addresses this gap by examining faculty perceptions of (1) factors influencing the recruitment and retention of students in STEM fields and (2) the role of STEM university faculty in student recruitment and retention.

\section{REVIEW OF RELEVANT LITERATURE}

One of the overarching goals of our research program is to determine if faculty are aware of the various factors that positively influence the recruitment and retention of students in STEM fields. Here, we briefly highlight those factors, starting with factors that affect recruitment into STEM fields and ending with factors that affect retention in STEM fields. This review of the literature provides context for our discussion of faculty comments about STEM recruitment and retention in the sections that follow.

\section{Factors Affecting Undergraduate STEM Recruitment}

According to the literature, students' decisions to pursue STEM-related majors in college are often shaped by their experiences and achievements before entering college (Astin \& Astin, 1992). In this section, we focus on the factors that are known to influence students' recruitment into STEM-related majors at the post-secondary level. The factors linked to students' choice to enter STEM fields after high school fall into two broad categories: (1) students' early interest in STEM-related fields and (2) students' STEM-related academic preparation.

Early interest in STEM-related fields. Students' early interest in and intention to major in STEM disciplines are factors that have been identified as strong predictors of student recruitment into STEM disciplines. Astin and Astin (1992) and Sullins et al. (1995) found that students who do not have an earlier commitment and intention to pursue a STEM career are less likely to become recruited into a STEM field. Students' attitudes toward STEM disciplines are also factors in the likelihood of their recruitment. For example, students' attitude toward math is an important indicator of whether or not they will choose to pursue a STEM major in college (Krantz, 1999; Perry, 2004).

STEM-related academic preparation. Students' STEM-related academic preparations are also strong predictors of their future recruitment into STEM fields. For example, students who are less proficient in mathematics or who lack self-efficacy in mathematics at the high school level are less likely to choose STEM disciplines in college (Astin \& Astin, 1992; Betz \& Hackett, 1983; Krantz, 1999; Perry, 2004). Similarly, the more science courses a student takes or the more a student becomes involved in scientific research or science-related clubs in high school, the more likely it is that the student will choose a STEM-related field during their postsecondary education (Astin \& Astin, 1992; Singh et al., 2002).

\section{Factors Affecting Undergraduate STEM Retention}

In the current section, we focus on three broad categories of factors that have been shown in the literature to influence the retention of undergraduates in STEM majors: (1) students' interactions with faculty, (2) students' interactions with peers, and (3) the environment of undergraduate science courses.

Interactions with faculty. Research emphasizes that faculty-student interactions can have a significant impact on students' persistence in a STEM-related field (Watkins \& Mazur, 2013). Two general types of student interactions with faculty can contribute to student persistence in STEM courses and programs of study: interactions that occur in the classroom and interactions that occur outside of the classroom.

Student/faculty interactions in the classroom. According to Seymour and Hewitt (1977), science students often perceive their interactions with faculty in the classroom as "cold". Personal classroom interactions with 
faculty in the college setting can have an important influence on students' choice of whether to continue in STEM. For example, Lichtenstein et al. (2007) concluded that "a single positive interaction [can] cause a student to confirm his or her choice to stick with engineering" (p.20).

Student/faculty interactions outside of the classroom. Although most student/faculty interactions occur within a classroom setting, student interactions with faculty outside of formal teaching settings are also found to positively impact student retention in STEM fields. Positive interactions out of the classroom such as those that occur during office hours, during a research forum, and/or in a laboratory, etc., can encourage students' continued commitment in STEM. Through interactions with faculty mentors, students gain mastery of content over time, develop successful student identities, and develop connections with their campuses. Each of these factors has been shown to promote persistence in STEM-related fields (Bounous-Hammarth, 2000). By guiding students outside of the classroom, faculty can establish mentoring relationships that lead to students' persistence in STEM fields (Bounous-Hammarth, 2000). Additionally, by engaging with students outside of the classroom, faculty are able to demonstrate a high level of concern for individual students and set high expectations for students' success, both of which can support student success and retention in STEM fields (Sullins et al., 1995). For example, 91\% of the 76 students interviewed about their experiences working with faculty members during undergraduate research reported personal and professional gains (Seymour et al., 2004).

Facilitating student participation in undergraduate research is considered particularly valuable and effective in promoting the retention of students (Nagda et al., 1998). Undergraduate research programs support meaningful interactions between students and faculty (Bounous-Hammarth, 2000) that help students view their faculty members as mentors and establish professional relationships outside of the classroom (Astin \& Astin, 1992). The positive relationships developed through undergraduate research programs positively influence the retention of students in STEM programs and increase the likelihood that students will continue to pursue graduate education (Thiry et al., 2011).

Interactions with peers. While positive faculty-student interactions are the most crucial factor affecting student retention in STEM fields, peer-to-peer relationships also have a significant effect. Previous research indicates that students' choice of majoring in a STEM field is positively correlated with their peers' choice. Astin and Astin (1992) found that a student is more likely to choose to major in biology if he/she has more peers also choosing to pursue biology. Students were also found to be more likely to graduate in physical sciences if their peers also chose a physical sciences major (Astin \& Astin, 1992).

Environment of undergraduate science courses. As previously mentioned, research suggests that many students do not hold positive views about the way they experience science learning in their classrooms (Osborne et al., 2003; Seymour \& Hewitt, 1977). According to Seymour and Hewitt (1977), most students who switch out of science majors (and most students who choose to stay in) perceived a poor quality of teaching in their science courses. These students described the presentation of information in their science courses as "dull" and disorganized (Seymour \& Hewitt, 1977).

The "environment" of a course, which includes factors like instructional approach, has an impact on student retention in STEM fields. Maltese and Tai (2011) found that when students enjoy learning an introductory science course in the classroom, they more likely to remain in a STEM discipline. Student-centered pedagogical approaches-such as student-peer instruction, contextualizing STEM content in subject matter important to students, and involving students in discussions about both STEM content and STEM careers-make introductory science classrooms more enjoyable and promote student persistence (Astin \& Astin, 1992; Maltese \& Tai, 2011; Watkins \& Mazur, 2013). Conversely, Baldwin (2009) found that students could be deterred from STEM subjects by the use of expository teaching styles, which are commonly employed in large lecture halls.

Other factors that contribute to a positive STEM classroom environment include smaller class sizes, low student-faculty ratios, high levels of cooperation among students, and an emphasis on research (Sullins et al., 1995).

Relevance to current study. Out of all the factors that potentially impact post-secondary students' recruitment and retention in STEM fields, our interests lie in the influence of faculty interactions on student recruitment and retention in STEM. Given that there is a need for an increased number of STEM graduates and that STEM faculty can have a significant impact on student recruitment into and retention within STEM fields (Astin \& Astin, 1992; Sullins et al., 1995; Watkins \& Mazur, 2013), it is important to understand how faculty perceive the STEM pipeline and their roles in recruiting and retaining students in STEM. However, there are a limited number of studies that investigate faculty perceptions about STEM student recruitment and retention. This study aims to address that gap in the literature.

\section{PURPOSE OF THE CURRENT STUDY}

The purpose of the current study is to examine university STEM faculty perceptions of issues related to student recruitment and retention in STEM fields. We chose to study this population because STEM faculty are often seen 


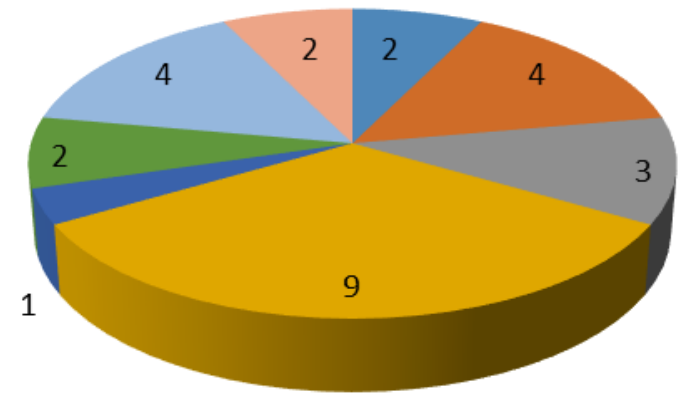

\author{
Biology \\ Chemistry \\ Computer Science \\ Engineering \\ - Geoscience \\ - Health Sciences \\ Mathematics \\ Physics
}

Figure 1. Distribution of faculty participants by STEM-related discipline

as the final "gatekeepers" of STEM pathways (Venville et al., 2013). Additionally, STEM faculty are considered pivotal in the successful implementation of STEM reform and educational enhancement initiatives (PCAST, 2012). For these reasons, it is important to understand how university STEM faculty view factors that impact the STEM education pipeline and what they perceive their roles to be in the recruitment and retention of STEM students.

We developed the following research questions to guide our examination of university faculty members' perceptions of recruitment and retention in STEM.

1. What are faculty perceptions of the gap between the number of STEM graduates and the number of available STEM-related jobs?

2. According to STEM faculty, why are students not going into STEM fields?

3. What are faculty perceptions of their roles in recruiting and retaining students in STEM fields?

\title{
METHODOLOGY
}

The data reported here come from a larger study that examines faculty perceptions of factors influencing student success in STEM fields (see Gandhi-Lee et al., 2015). The current study specifically explores faculty perceptions of recruitment and retention and faculty roles in these STEM educational efforts. Phenomenography was employed as the theoretical framework for this study. Phenomenography is an empirical research tradition that was designed to answer questions about thinking and learning, especially in the context of educational research (Marton, 1986; Orgill, 2007). Its aim is to define variety of ways in which a particular group of people experience, interpret, understand, perceive, or conceptualize a certain aspect of reality.

In order to address the research questions, we interviewed 27 STEM faculty, with expertise in multiple STEM disciplines at a Southwestern research university (Figure 1). All participants were tenure-track faculty, ranking from Assistant to Full Professor, with typical appointments of 40\% research, 40\% teaching, and 20\% service. All participants were currently teaching or had recently taught lecture and/or laboratory courses in their disciplines. Participation was voluntary; therefore, the distribution of the faculty members interviewed is not representative of the university. Interviews were conducted in a semi-structured and conversational format, lasting approximately 30-45 minutes. Interviews were both open and deep. They were open in that, while the interviewers had a list of literature-based questions and concerns they wished to address during the interview, they were also free to follow unexpected topics brought up by the interviewees. They were deep in that the interviewers asked follow-up questions until (1) they were sure they understood what the interviewees meant by their responses and/or (2) the interviewee had no more to say about a particular line of questioning (Orgill, 2007). Here, we describe the portion of the interview relevant to the current study. For a discussion of the other questions asked during the interview, please see Gandhi-Lee et al. (2015).

The interview guide was developed by four researchers (EG, EM, PS, MO) who, as a group, have expertise in biology, chemistry, engineering, mathematics, educational technology, and educational research. They used a grounded approach to identify categories of factors that have been shown by research to support student success in STEM and wrote initial versions of interview questions that would allow participants to comment about each of these categories. Interview questions were then modified for consistency with the project goals and research questions. The interview guide was finalized once each of the aforementioned researchers agreed that the questions 
were (1) clear, (2) consistent with the literature, and (3) consistent with the project goals. Interviewers began by asking faculty participants to describe their educational backgrounds, their research, and the classes they typically teach. Then, interviewers asked faculty to discuss growing national concerns about recruitment and retention in STEM fields at the post-secondary level; to hypothesize as to why students either (1) do not enter STEM fields or (2) choose to leave STEM fields; and to describe their roles in addressing STEM recruitment and retention. An abbreviated version of the interview guide, which lists potential interview starter prompts that are relevant to the current study, can be found in Appendix A. Follow-up questions are not listed, as they differed by participant, depending on each participant's response to the initial prompt.

Each interview was transcribed verbatim. Three researchers (EG, HS, MO) examined the transcripts for evidence of faculty members' perceptions related to each of the three research questions (e.g., faculty perceptions about why students are not going into STEM fields). The same researchers used investigator triangulation to establish the validity and trustworthiness of the data analysis and results (Johnson, 1997). During multiple meetings that occurred over several months, the researchers met to discuss the categories they had identified through their individual analyses and to develop a common set of categories that could be used to describe the transcript data, coming to consensus on a description of each category. They then reexamined the transcripts to make sure the consensus categories were descriptive of the data while, at the same time, looking for evidence of themes that had not been initially considered. No additional themes emerged during this analysis. As a final level of analysis, they developed three theme-based assertions describing faculty perceptions of (1) growing national concerns about recruitment and retention in STEM fields, (2) possible reasons students do not enter or remain in STEM fields of study, and (3) their roles in student recruitment and retention in STEM fields. In the sections that follow, we provide these assertions and the evidence that supports each of them.

\section{RESULTS}

\section{Assertion 1}

A majority of the interviewed faculty were either unaware of or not worried about national concerns about STEM recruitment and retention.

When we asked faculty to comment on the reported national concerns related to STEM recruitment and retention, we found that of the 27 faculty interviewed, 15 were unaware of them, 9 were aware of them but not worried about them, and one participant was unsure about his opinion on the matter. Two participants did not provide a direct response about the national concerns. Below, we report briefly on (1) the responses of the first group of faculty, those who were unaware of the national concerns and (2) the reasons why the second group of faculty were not worried about these national concerns.

Faculty participants who were unaware of national concerns related to STEM education were focused on the enrollments in their own courses. A majority (15) of the faculty did not seem to be aware of the national concerns about recruitment and retention in STEM fields. The STEM education focus of these faculty members seemed to be more on the fact that enrollments in their own classrooms — or even in their own disciplines_-have increased in recent years than about what is happening on a national, or even global, level.

I'm not sure the geoscience is actually declining. I think that we're seeing — as of late, in the past five years, like our numbers have gone up pretty significantly.... And, looking at the future, we're going to need a whole lot more geoscientists so there should be even more coming. (Dr. Peyton, Geoscience)

Faculty who were not worried about national concerns related to STEM education did not perceive a need to produce more STEM graduates. We asked the group of faculty (9) who were aware of but not worried about national concerns related to STEM recruitment and retention to describe why they were not worried. Members of this group stated that there is no need to produce more STEM graduates for two main reasons: (1) faculty perceived that there are not currently enough employment opportunities for STEM graduates and (2) faculty perceived that any available STEM jobs could be easily filled by an international workforce.

STEM graduates may not find jobs. Four faculty participants expressed their perception that there is an uncertain job market for STEM graduates. Thus, producing more STEM graduates may not be necessary.

There is a certain size job market that could really be supported by chemistry majors. And I think that if we were to double the number of chemistry majors coming out of universities, I don't know that the U.S. labor market would develop twice as many job for chemistry majors. On the other hand, I'm not at all convinced that in chemistry, specifically, there's a need for a lot more chemists than are currently being produced. (Dr. Rios, Chemistry)

STEM jobs could be filled by international workers. Two participants were unconcerned about the national gap between the number of U.S. STEM graduates and the number of available STEM-related jobs because jobs can always be filled by international workers. Dr. Javier's (Computer Science) comments reflect this rationale: 
There are a lot of international students, so I don't think America is a risk of not having a supply of engineers. [...] I mean, I think one would always be able to fill jobs as long as there are enough visas for people to come to the country.

\section{Assertion 2}

Faculty perceived that students do not choose to enter or remain in STEM fields because they have negative perceptions about STEM fields, or because they lack the dedication, training, or familial support they need to be successful in STEM fields.

Faculty participants were also asked to speculate as to why students do not choose to enter or stay in STEM fields. Here, we discuss four factors that faculty believe have a negative impact on STEM student recruitment and retention: (1) students carry negative perceptions about STEM fields, (2) students lack the dedication needed to persist in STEM fields, (3) students lack adequate academic preparation to succeed in STEM fields, and (4) students lack familial role models that can encourage them to enter or remain in STEM fields.

Faculty perceived that students have negative perceptions of STEM fields. Multiple faculty (4) suggested that many students do not go into STEM fields because they have negative perceptions of those fields. "Typically the so-called STEM fields are considered more difficult and that [...] translates into fewer students going into it" (Dr. Lee, Mechanical Engineering). Dr. Burt (Life Sciences) noted that there are also negative stigmas associated with those who pursue careers in STEM disciplines. For example, STEM students can be labeled "geeks".

I think [studying a STEM discipline is] daunting. [...] We have to celebrate the geek (laughs)....my little crusade.

I think [...] we've got to stop making people think that [...] there's a stigma attached to thinking, you know.

We've got to embrace that. We've got to try to encourage that and, you know, embrace the geek [...]. I think students should be made to feel proud of the fact that they're thinking about things, and I don't think we do enough in promoting that kind of thing, unfortunately.

Two faculty members expressed concerns that some of the negative perceptions that students have about STEM fields may be related to how STEM content is conveyed to students during their K-12 education. They stated that if the K-12 STEM curriculum is discouraging and inaccessible-or doesn't encourage students who show interest in and an aptitude for STEM fields - then students will continually resist entering STEM fields.

Faculty perceived that students are unaware of or lack the dedication that STEM requires. Faculty (3) perceived that students are either not aware of the high level of dedication that STEM work requires or are unwilling to commit to this high level of dedication.

You know, [STEM is] hard. Science requires focus. It's hard to be in a lab for hours. We'll go to A----- National Laboratory. We do a lot of experiments; we'll be there for 10 hours straight. We don't even think about it; and that's how it is sometimes, because you've got to do it until you get it right. And, so, we need to foster these students who are going to be willing to go through this struggle for science. (Dr. Rogers, Physics)

Another faculty member in the Health Sciences, Dr. George, made a similar comment:

I think they're afraid to work, afraid to be challenged. Many of the students seem to have a sense of entitlement; and they're just not gonna make it with that attitude.

Faculty perceived that students are not adequately prepared for STEM classes or majors in college. Some faculty members (2) described students' inadequate academic preparation prior to college as a reason for their attrition from STEM majors at the post-secondary level. They perceive that students do not enter college with sufficient background knowledge in mathematics and science and/or the necessary skills to succeed in college STEM courses. Speaking specifically to math skills, Dr. Rogers (Physics) summarized this notion: "The biggest problem with students in the introductory [physics] courses is that they just don't have the mathematical sophistication that they need. Math is our language."

Faculty perceived that many students lack familial STEM role models that can encourage students to enter or remain in STEM fields. Two faculty participants suggested that many students lack familial STEM role models that could encourage them to pursue and persist in a STEM major. These faculty members recognized that this is a particular obstacle for many students from underrepresented populations.

One of the reasons [students don't go into STEM fields] is the background of that student at home. A presence of a family member who is in the STEM field would, could trigger interest for a child to go into STEM field.

And, we know that the typical underrepresented communities in the U.S. don't have STEM-related [...] family members. (Dr. Hester, Civil and Environmental Engineering)

Dr. Schrute (Environmental Engineering) echoed this concern and emphasized the need for potential STEM students from any background to have familial support at an early age: "I think [students] need to have encouragement at home [to go into a STEM field]. I think they need to have encouragement in, you know, starting from middle school." 


\section{Assertion 3}

Most interviewed STEM faculty members did not recognize that they could or should play a role in STEM recruitment and retention. The few faculty members who recognized that they could influence STEM recruitment and retention focused on K-12 outreach efforts instead of on what they could do in their own classrooms.

A majority of the faculty participants (22 out of 27) did not recognize that they could or should have an active role in addressing recruitment and retention issues in STEM education. For example, Dr. Clark (Mathematics) said, "[...] I've thought about [getting involved in STEM recruitment and retention], and, generally, decided, at this point in my career, it didn't seem to match my own personal goals." Dr. Rios (Chemistry) responded similarly: "Right now I'm trying reduce the number of commitments I'm making just because I feel like I've got more to do than I've got time to do."

How faculty contribute to STEM recruitment and retention efforts. There were only five faculty participants who not only felt responsible for STEM recruitment and retention, but who discussed specific ways in which they were involved in these efforts. For these faculty, STEM recruitment and retention efforts focused exclusively on periodic K-12 outreach activities, which they described only briefly. Such activities included providing presentations at local middle schools, working at community STEM fairs, and working collaboratively with individual K-12 teachers and students. For example, Dr. Javier (Computer Science) discussed his involvement in educational outreach efforts in the community: "Well, I've given presentations in the minority engineering program, $[\ldots]$ and I've gone to schools — even to middle schools—and I've shown some combinatorial stuff that was actually fun..." Dr. Rogers (Physics), who has been involved in K-12 outreach efforts in the past, described ways in which he planned to be involved in the future:

I'm planning to propose I visit those classrooms once a month, and pick one concept from their curriculum, from what they are learning in the classroom, from their teacher, and I will just go there, and take an hour to take them through an activity of building or physical model to help them build those linkages in their brains.

That will create a permanent learning on which they can build their future learning.

Although, as previously mentioned, faculty can have a significant on STEM retention at the post-secondary level, none of the faculty we spoke with mentioned conscious efforts to recruit or retain students at that level.

\section{DISCUSSION}

As experts of their fields and gatekeepers of the STEM experience in college, faculty provide important perspectives into issues related to post-secondary STEM recruitment and retention. As key stakeholders in the STEM pipeline, they are in a position to positively influence STEM education. As such, their understanding of how recruitment and retention is impacting tertiary STEM education gives us valuable insights from the insiders' perspective and for future research. Specifically, the results of the current study provide key insights into faculty perceptions of (1) national concerns about recruitment and retention in STEM education, (2) possible reasons students either do not enter or remain in STEM fields of study, and (3) their roles in student recruitment and retention in STEM fields.

\section{Assertion 1}

Our findings from first category suggest that most faculty maintained a local perspective of the issues at stake and were unaware of more global issues facing STEM education. First, faculty perceptions about recruitment and retention in STEM were mainly informed by enrollment in their own courses, rather than being informed by research or by national or global trends in enrollment. Additionally, this study suggests that faculty may be more aware of numbers related to student enrollment in STEM fields rather than numbers related to student persistence in STEM fields. That is, faculty seem to know how many students enter their individual classes, but they do not know how many of those students go on to complete a degree in a STEM field. National reports suggest that past efforts to improve the flow of students into STEM primarily affected enrollment numbers, but failed to yield longlasting results in student persistence (Sims, 1992). The National Science Foundation (NSF) spent over \$1.5 billion in the 1990s, and programs at the National Institute of Health spent $\$ 675$ million in STEM recruitment efforts (Sims, 1992). Although these recruitment initiatives showed a spike in enrollments of students in science, math and engineering majors, the attrition rates of students remained unchanged (Seymour, 2001). This suggests that faculty may be witnessing high numbers of incoming freshmen enrollment in introductory STEM courses, but do not follow the high switch-out and attrition rates in STEM majors during the latter years of college. Second, faculty who were unconcerned about STEM recruitment and retention did not perceive a positive employment outlook for STEM graduates, despite studies that indicate that there are more STEM-related jobs than there are qualified candidates. Recent literature reports that it is increasingly common for students with degrees in the physical sciences to employ their STEM skills in non-traditional (and non-bench) jobs working, for example, as teachers, 
medical technicians, information technologists, manufacturing technologists, etc. (Bales, 2006). This finding suggests that faculty may not be considering non-traditional jobs in their perceptions of the STEM job market and/or that they may not recognize that the skills students develop as they earn degrees in STEM fields are applicable in jobs beyond those traditionally held by STEM graduates.

\section{Assertion 2}

Our findings from the second assertion indicate that faculty perceived various reasons for students not pursuing STEM-related majors and careers. Some reasons were related innately to students' own perceptions, expectations, and readiness, while other reasons were related to environmental factors such as a lack of support at home for students entering STEM-related fields or a lack of K-12 engagement in STEM topics in the K-12 years. Each of the factors that faculty identified as potentially affecting student recruitment and retention into STEM were related to experiences that happened outside of the post-secondary classroom. However, faculty participants did not mention factors in their own classes and disciplines that may be contributing to STEM recruitment and retention. Research emphasizes that teaching practices and positive faculty interactions in STEM courses in college play a critical role in students' choice to persist in STEM majors (Baldwin, 2009; Lichtenstein et al., 2007; Watkins \& Mazur, 2013); however, the results of the current study suggest that faculty may be unaware of the high level of impact they can have on student retention or of the effect of their classroom teaching practices on students' persistence in STEM majors.

\section{Assertion 3}

Research has shown that university faculty have the potential to directly impact student retention by their classroom practices and attitudes toward students (Astin \& Astin, 1992; Lichtenstein et al., 2007; Watkins \& Mazur, 2013). However, our findings from the third assertion showed that the small number of faculty who did feel some responsibility to influence STEM recruitment and retention mainly focused on their outreach work in local school districts. The fact that faculty focused on K-12 outreach and not on what they could do in their own classrooms to improve STEM recruitment and retention suggests that faculty may be (1) unaware of the substantial impact that reforming their own courses and/or their own interactions with students can have on STEM recruitment and retention, (2) unmotivated to make the corresponding changes in their practice, or (3) unsure about how to alter their practices to benefit STEM recruitment and retention.

Low levels of faculty involvement in efforts to improve their classroom instruction have been attributed to institutional reward systems that primarily reward faculty based on their research accomplishments and publications (Baldwin, 2009; PCAST, 2012; Schwartz, 2012). For example, Schwartz's (2012) study reported that many faculty perceived that their efforts to support students in or outside of the classroom were undervalued by their administration for tenure and promotion purposes. Moreover, even faculty who were motivated to improve their classroom practice often lacked the time and resources to do so. One important resource that is often lacking for STEM faculty is knowledge of reform-based pedagogical practices and their implementation. Although STEM faculty may be experts in their own disciplines, they are not often experts in teaching (Sunal et al., 2001). As such, professional development about the implementation and impact of research-based pedagogies may be an important component in helping university STEM faculty realize their potential in addressing issues related to STEM recruitment and retention at the post-secondary level in the future (Sunal et al., 2001).

\section{LIMITATIONS OF THE CURRENT STUDY}

The results of this study are somewhat limited because of the nature of the participant population selected for this study. First, university faculty were all selected from the same university for the current project. Consequently, their experiences with students and their perceptions about STEM pipeline issues could possibly be similar. Therefore, future research could potentially enhance this study by including faculty from different institutions and different types of institutions (i.e., research-intensive, primarily undergraduate, 2-year college, etc.) as participants. Second, because participation in the current project was voluntary, (1) the participant population in this study is not representative of the numbers of faculty in different STEM disciplines on campus and (2) the group of faculty selected does not include many faculty from particular STEM disciplines. For example, although the biology department is one of the largest STEM departments at this particular university, only two biology faculty members chose to participate in this study. It may be that faculty perceptions of STEM recruitment and retention differ by discipline, but we were not able to determine this because of the small number of participants from certain disciplinary backgrounds. Future work should compare the perceptions of university STEM faculty from different disciplines (for example, mathematics faculty perceptions of the STEM pipeline could be compared with the perceptions of biology faculty). Despite the limitations discussed here, the current study is beneficial in providing 
important insights directly from the faculty members at a major university about how they view STEM recruitment and retention.

\section{CONCLUSIONS}

It is clear from previous studies that university STEM faculty members can significantly affect student recruitment and retention in the STEM pipeline. However, according to the results of the current study, faculty may be unaware of both the shortage of STEM graduates at the national level and of the reasonable actions they can take to positively impact STEM recruitment and retention at the post-secondary level. The current study is a first step in examining university STEM faculty beliefs about factors affecting the flow of students into and through the STEM pipeline. Future studies could focus not only on the beliefs of an expanded set of university STEM faculty but also on identifying the knowledge, resources, and training that faculty need in order to make changes that support STEM student recruitment and retention.

\section{REFERENCES}

Astin, A. W., \& Astin, H. S. (1992). Undergraduate science education: The impact of different college environments on the educational pipeline in the sciences. Los Angeles, CA: University of California, Graduate School of Education, Higher Education Research Institute.

Baldwin, R. G. (2009). The climate for undergraduate teaching and learning in STEM fields. New Directions for Teaching and Learning, 117, 9-17.

Bales, L. (2006). Nontraditional Careers for Chemists: Physicists and Astronomers. Bureau of Labor Statistics, U.S. Department of Labor, Occupational Outlook Handbook. Retrieved from http://www.bls.gov/ooh/lifephysical-and-social-science/physicists-and-astronomers.htm

Betz, N. E., \& Hackett, G. (1983). The relationship of mathematics self-efficacy expectations to the selection of science-based college majors. Journal of Vocational Behavior, 23, 329-345.

Breiner, J. M., Harkness, S. S., Johnson, C. C., \& Koehler, C. M. (2012). What is STEM? A discussion about conceptions of STEM in Education and Partnerships. School Science and Mathematics, 112, 3-11.

Brown, P. L., Abell, S. K., Demir, A., \& Schmidt, F. (2006). College science teachers' views of classroom inquiry. Science Education, 90, 784-802.

Bounous-Hammarth, M. (2000). Pathways to success: Affirming opportunities for science, mathematics, and engineering majors. Journal of Negro Education, 69, 92-111.

Change the Equation Vital Signs: Reports on the condition of STEM learning in the U.S. (2010) STEM Help Wanted: Demand for Science, Technology, Engineering and Mathematics weathers the storm. Retrieved August 30, 2016, from http://changetheequation.org/sites/default/files/CTEq_VitalSigns_Supply\%20(2).pdf.

Cejda, B. D., \& Rhodes, J. H. (2004). Through the pipeline: The role of faculty in promoting associated degree completion among Hispanic students. Community College Journal of Research and Practice, 28, 249-262.

Chen, X. (2013). STEM attrition: College students' paths into and out of STEM fields (NCES 2014-001). National Center for Education Statistics, Institute of Education Sciences, U.S. Department of Education. Washington, DC.

Gandhi-Lee, E., Skaza, H., Marti, E., Schrader, P.G., \& Orgill, M. (2015). Faculty perceptions of the factors influencing success in STEM fields. Journal of Research in STEM Education, 1(1), 30-44.

Johnson, R. B. (1997). Examining the validity structure of qualitative research. Education, 118(2), 282-292.

Krantz, S. G. (1999). How to teach mathematics. Providence: American Mathematical Society.

Lichtenstein, G., Loshbaugh, H. G., Claar, B., Bailey, T. L., \& Sheppard, S. (2007). Should I stay or should I go? Engineering students' persistence is based on little experience or data. In Proceedings of the American Society for Engineering Education Annual Conference, Honolulu, Hawaii.

Maltese, A. V., \& Tai, R. H. (2011). Pipeline persistence: Examining the association of educational experiences with earned degrees in STEM among U.S. students. Science Education, 95, 877-907.

Marton, F. (1986). Phenomenography - A research approach to investigating different understandings of reality. Journal of Thought, 21(3), 28-49.

Nagda, B. A., Gregerman, S., Jonides, J., von Hippel, W., \& Lerner, J. (1998). Undergraduate student faculty research partnerships affect student retention. The Review of Higher Education, 22, 55-72.

National Science Board. (2015). Revisiting the STEM workforce: A companion to science and engineering indicators 2014. Arlington, VA: National Science Foundation.

National Center for Education Statistics [NCES]. (2008, March). Digest of Education Statistics. Science and engineering indicators. Retrieved August 25, 2016, from http://nces.ed.gov/pubs2009/2009020.pdf. 
Orgill, M. (2007). Situated Cognition. In G. M. Bodner \& M. Orgill (Eds.), Theoretical frameworks for research in chemistry/science education (pp. 187-203). Upper Saddle River, NJ: Pearson Education Publishing.

Osborne, J., Simon, S., \& Collins, S. (2010). Attitudes towards science: A review of the literature and its implications. International Journal of Science Education, 25(9), 1049-1079.

Perry, A. (2004). Decreasing math anxiety in college students. College Student Journal, 38, 321-334.

President's Council of Advisors on Science and Technology [PCAST]. (2012). Engage to excel: Producing one million additional college graduates with degrees in Science, Technology, Engineering and Mathematics. Retrieved November 16, 2013 from http://www.whitehouse.gov/

Schwartz, J. (2012). Faculty as undergraduate research mentors for students of color: Taking into account the costs. Science Education, 96(3), 527-542.

Seymour, E. (2001). Tracking the processes of change in U.S. undergraduate education in science, mathematics, engineering, and technology. Science Education, 86(1), 79-105.

Seymour, E., \& Hewitt, N. M. (1997). Talking about leaving: Why undergraduates leave the sciences. Michigan: Westview Press.

Seymour, E., Huner, A., Laursen, S. L., \& Deantoni, T. (2004). Establishing the benefits of research experiences for undergraduates in the sciences: First findings from a three-year study. Science Education, 88, 493-534.

Sims, C. (1992). What went wrong: Why programs failed. Science, 258(5085), 1185 - 1187

Singh, K., Granville, M., \& Dika, S. (2002). Mathematics and science achievement: Effects of motivation, interests, and academic engagement. The Journal of Education Research, 95, 323-323.

Sullins, E. S., Hernandez, D., Fuller, C., \& Tashiro, J. S. (1995). Predicting who will major in a science discipline: Expectancy-value theory as part of an ecological model for studying academic communities. Journal of Research in Science Teaching, 32, 99-119.

Sunal, D. W., Sunal,C. S., Whitaker, K. W., Freeman, L. M., Odell, M., Hodges, J., Edwards, L., \& Johnston, R. A. (2001). Teaching science in higher education: faculty professional development and barriers to change. School Science and Mathematics, 101(5), 246-257.

Thiry, H., Laursen, S. L., \& Hunter, A.-B. (2011). What experiences help students become scientists? A comparative study of research and other sources of personal and professional gains for STEM undergraduates. The Journal of Higher Education, 82, 357-388.

U.S. Department of Commerce. Economics and Statistics Administration. (2011, July). STEM: Good jobs now and for the future. Retrieved August 30, 2016, from http://www.esa.doc.gov/sites/default/files/stemfinalyjuly14_1.pdf.

Venville, G., Rennie, L., Hanbury, C., \& Longnecker, N. (2013). Scientists reflect on why they chose to study science. Research in Science Education, 43, 2207-2233.

Watkins, J., \& Mazur, E. (2013). Retaining students in Science, Technology, Engineering, and Mathematics (STEM) majors. Journal of College Science Teaching, 42, 36-43. 


\section{APPENDIX A}

\section{ABBREVIATED INTERVIEW PROTOCOL}

\section{Demographics}

a. Tell me a little about yourself (i.e. How long have you been teaching here? Have you taught anywhere else? Where did you go to school? What kind of research do you do?)

b. What kinds of classes do you teach here?

c. What are the majors of the students in those classes?

d. Do you feel like your students are prepared for your classes? Why?

i. If yes, what makes them prepared?

ii. If no, what are those students lacking? What would help them be better prepared for your classes?

\section{II. [Questions not relevant to the current study have been deleted.]}

\section{Recruitment and Retention in STEM Areas of Study}

[The basic questions listed below guided conversations with faculty. The interviewers followed up each of these guiding questions with further questions to ensure that they understood the faculty member's answer in detail. Corresponding research questions are indicated in red font.]

a. [Research Questions 1 and 2] Recent research shows that the number of students in STEM majors is declining.

i. People seem to be concerned about the decline in the number of students in STEM majors. Do you agree with them? Why or why not?

ii. Why do you think there are fewer students in STEM majors?

b. [Research Question 2] What do you think students should be doing to prepare themselves before they enter a STEM major in college?

i. What kinds of classes should they be taking?

ii. What should they be doing?

iii. What traits or characteristics should they develop?

c. [Research Question 2] What do you think pre-college teachers could do to prepare their students to enter a STEM major?

d. [Research Question 3] What do you think faculty at the University can do to help students prepare to be successful in STEM majors?

i. (Explore whether the faculty are involved in such efforts—and how—or if they are willing to be involved in such efforts.)

\section{IV. [Questions not relevant to the current study have been deleted.]}

